\title{
Rancang Bangun Produk Permainan Edukasi untuk Anak Usia 10 Tahun dengan Pendekatan Peristiwa Sejarah Bangsa Indonesia Sesuai Kurikulum 2013
}

\author{
Fatchur Rizqi dan Bambang Tristiyono \\ Desain Produk Industri, Fakultas Arsitektur Desain dan Perencanaan, Institut Teknologi Sepuluh Nopember (ITS) \\ Jl. Arief Rahman Hakim, Surabaya 60111 Indonesia \\ e-mail: gacombi@prodes.its.ac.id
}

\begin{abstract}
Abstrak-Pada pembelajaran disekolah sudah menjadi permasalahan yang umum apabila anak didik jenuh dengan suatu pelajaran yang diajarkan, terutama pelajaran yang banyak melibatkan hapalan. Pelajaran sejarah merupakan salah satu pelajaran yang membosankan baik bagi pengajar maupun murid. Oleh sebab itu diperlukan pendekatanpendekatan yang berbeda dalam pengajaran tersebut agar anak lebih tertarik mendengarkan dan menanam minat pada suatu pelajaran, salah satu metode paling ampuh adalah melakukan simulasi permainan. Bermain merupakan hal yang wajib dilakukan anak untuk menghindari semua tekanantekanan yang mungkin mereka alami di sekolah atau lingkungan sekitar, mereka memainkan jenis permainan apapun baik fisik maupun digital seperti saat ini. Boardgame adalah salah satu jenis permainan fisik yang menarik untuk dimainkan, selain itu boardgame sendiri dapat mengurangi dampak negatif dari kecanduan anak terhadap gadget saat ini. Permainan boardgame bila dilakukan disuatu instansi pendidikan harus ditinjau aspek durasi karena setiap instansi pendidikan, terutama sekolah dasar memiliki batasan durasi yang sangat sedikit. Metode hapalan dengan bacaan dan gambar dikembangkan dengan cara mengunakan komponenkomponen berwujud 3 dimensi sehinga peserta didik dapat memegang secara langsung dan lebih mudah mengenali peristiwa yang terjadi pada sejarah tanpa harus melihat gambar 2 dimensi pada buku pelajaran mereka.
\end{abstract}

Kata Kunci-Education, Boardgame, History.

\section{PENDAHULUAN}

$\mathrm{K}$ ONDISI belajar mengajar pada sekolah dasar saat ini menggunakan kurikulum 2013, kurikulum tersebut memiliki 2 metode pengajaran yaitu langsung dan tidak langsung. Dalam pembelajaran langsung tersebut peserta didik melakukan kegiatan belajar dengan cara mengamati, menanyakan, mengumpulkan informasi, mengasosiasi atau menganalisis, dan mengkomunikasikan apa yang sudah ditemukannya dalam kegiatan analisis. Akan tetapi siswa cenderung masih sering mengalami kejenuhan dalam proses belajarnya, tingkat kejenuhan belajarnya berada di dalam kategori cukup tinggi prosentasinya, area keletihannya berada di area keletihan emosi. Jika kejenuhan belajar siswa terus berada dalam kategori tersebut maka siswa akan cenderung untuk meninggalkan tugas-tugas mereka [1].

Kejenuhan belajar merupakan salah satu jenis kesulitan yang sering terjadi pada anak, secara harfiah kejenuhan berarti padat atau penuh sehinga tidak dapat menerima atau memuat apapun. Kejenuhan yang dialami siswa dapat menyebabkan usaha belajar yang dilakukan sia-sia, disebabkan karena akal yang tidak bekerja sebagaimana mestinya dalam memproses informasi atau pengalaman yang baru diperoleh [2].
Hal tersebut dialami seperti pada pendidikan budi pekerti ataupun sejarah, pendidikan tersebut dirasa sangat menyulitkan dan membosankan bagi siswa dan guru karena pendidikan semacam itu hanya disampaikan melalui hafalan-hafalan atau sikap-sikap baik dan buruk dalam nilainilai budi pekerti tanpa diadakan pembiasaan tingkah laku, dan lain lain [3].

Oleh sebab itu, pendekatan dalam pembelajaran yang berbeda diperlukan. Disamping itu juga adanya perlakuan khusus terhadap mereka. Mereka memiliki konsep berpikir yang berbeda. Lingkungan yang mereka temui bukan hanya pada alam nyata, akan tetapi juga alam maya. Mereka bersosialisasi secara virtual dan nyata, mereka menggali dan mendapatkan informasi dengan cepat dan aktual. Dan mereka dengan sangat senang mengambil semua yang mereka anggap menyenangkan ke dalam kehidupan mereka [4].

Cara yang menarik untuk melakukan pembelajaran yaitu menggunakan simulasi permainan, salah satunya adalah boardgame. Beberapa keuntungan dari permainan boardgames, antara lain: Siswa dapat melakukan "simulasi" dari suatu "peristiwa" sehingga mendapatkan pengalaman belajar secara langsung (Experential Learning), siswa dapat melakukan proses belajar dalam bentuk: komunikasi, negosiasi, kerja tim, kepemimpinan, pengambilan keputusan, dan menghadapi resiko, guru dapat memantau langsung hasil belajar dari materi yang diberikan

Simulasi permainan juga dapat mempengaruhi edukasi para pemainnya, karena mereka dapat belajar hal hal yang baru ketika bermain. Permainan ini juga mengajak anak untuk sabar serta berpikir secara runtut, mulai dari awal giliran mereka sampai selesai lalu dilanjutkan pemain lainnya.

Pada sisi dunia pendidikan, permainan apapun dapat membuat ilmu lebih mudah masuk, karena anak-anak langsung merasakan dan melakukan hal itu dan hal tersebut membuat mereka senang. Dengan permainan terutama boardgame anak-anak diajak berpikir secara berurutan, hal ini menjadi pondasi utama dalam mengembangkan desain boardgame yang dapat membuat anak lebih senang dan lebih dapat mengerti pelajaran sejarah dengan cara bermain.

\section{METODOLOGI}

\section{A. User Interview}

User interview dilakukan pada acara talkshow "boardgame for education" pada acara Surabaya Boardgame Market pada tanggal 15 Oktober 2016 di Ciputra World dengan seorang guru SD Al-Azhar 35 serta seorang guru Homeschooling. Interview dilakukan setelah 
sesi talkshow berakhir, selama talkshow juga diadakan sesi tanya jawab yang ikut membantu pengumpulan data dalam proposal ini.

Interview berikutnya dilakukan pada guru SD Al-Azhar yang lain untuk menemukan pendapat yang berbeda dari masing-masing pengajar.

Data yang diperoleh melalui metode ini antara lain:

- Kurikulum Pengajaran: Penggunaan kurikulum pada sekolah sebagai acuan dalam permainan yang akan dirancang agar sesuai dengan kurikulum yang diajarkan.

- Metode pengajar: Mengetahui bagaimana pengajar biasa mengajarkan pelajaran ke peserta didiknya, mengetahui apakah layak suatu permaianan dijadikan sebagai suatu metode pengajaran.

- Durasi Pengajaran: Mengetahui seberapa lama durasi mengajar yang nantinya membatasi durasi permainan yang akan dirancang.

\section{Shadowing}

Shadowing dilakukan selama acara Surabaya Boardgame Market berlangsung, yaitu selama 3 hari, 14 Oktober-16 Oktober 2016. Shadowing dilakukan dengan cara mengamati aktivitas pemain dari segala range usia serta ekspresi yang mereka utarakan mulai dari permainan dimulai hingga berkhirnya permainan.

Data yang diperoleh melalui metode ini antara lain,

- Acuan Permainan : Mengetahui jenis permainan yang sesuai dengan target usia.

- Durasi Permainan : Mengamati durasi beberapa jenis permainan sebagai perbandingan dengan durasi pengajaran.

- Aktifitas Pemain : Mengamati aktifitas mereka dari awal permainan, selama bermain, serta di akhir permainan.

\section{Affinity Diagram}

Metode yang digunakan untuk mengelompokkan masalah yang ada dari fenomena-fenomena yang disimpulkan dari pengumpulan data sebelumnya.

\section{Eksplorasi Ide}

Sketsa Brainstroming; hasil dari data primer dan sekunder disatukan kemudan diproses kembali melalui sketsa-sketsa kasar yang dapat memunculkan ide baru.

\section{Pemilihan Desain Alternatif}

Hasil dari eksplorasi ide dipilih dan dikerucutkan mencadi desain alternatif yang sesuai dengan indikator yang sesuai berdasarkan hasil riset dan desain.

\section{Studi dan Analisis Desain}

Alternatif yang telah terpilih dikembangkan menjadi lebih detail dengan bantuan riset-riset yang telah dilakukan dan sesuai dengan konsep desain seperti aspek teknis, bentuk, dan semacamnya.

\section{Pengembangan Desain}

\section{- Studi Model}

Studi selanjutnya membuat model/purwarupa untuk menemukan bentuk serta fungsi teknis yang cocok dan dapat disatukan dengan desainnya nanti. Seperti menemukan bentuk serta alat pemutar yang cocok sebagai spinner pada boardgame nantinya.
- Digital modeling

Desain yang terpilih disimulasikan secara digital untuk memudahkan mendapatkan alternatif hingga tewujud desain final.

\section{Prototyping}

Final desain yang terpilih direalisasikan dengan wujud aslinya berskala 1:1 dengan menggunakan $100 \%$ material aslinya.

\section{Usability Test}

Tahap akhir adalah mencoba prototype digunakan pada user aslinya baik target user secara langsung maupun pengganti user.

\section{KONSEP DAN ANALISIS}

\section{A. Konsep Desain}

Ide dan eksperimen telah dilakukan dan diproses untuk menemukan konsep desain melalui brainstorming, seperti berikut:

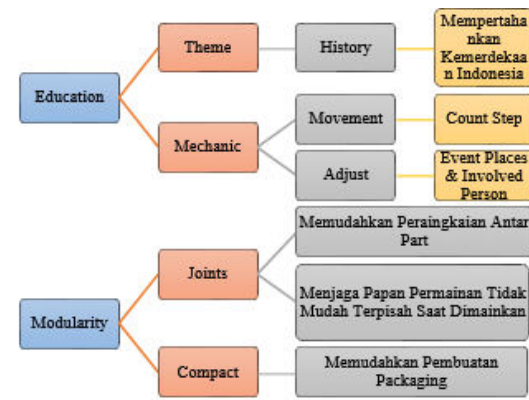

Gambar 1. Skema Brainstorming Konsep

Dari hasil brainstorming diatas memunculkan 2 kata kunci pada konsep desain meliputi :

1. Education: Mengambil tema berupa pendidikan sejarah yang sesuai dengan apa yang diajarkan ke anak sekolah dasar kelas $\mathrm{V}$ tentang kemerdekaan Indonesia, mengaplikasikan tema yang sesuai pada komponen boardgame untuk menunjang nilai edukasi pada target utama.

2. Modularity: Produk terbagi menjadi bagian-bagian kecil dan terpisah kemudian dirangkai menjadi satu modul yang utuh, mudah dibongkar-pasang, memudahkan proses pembuatan packaging karena lebih ringkas.

\section{B. Analisis Roleplay (Cara Bermain)}

Roleplay permainan menggunakan metode collecting, serta mix and match. Pemain menjalankan bidak mengelilingi area yang sudah ditentukan pada papan permainan. Dipadukan dengan metode race, pemain diharuskan memperoleh event place secara lengkap, yang tercepat dia yang memenangkan permainan. Pemain dapat memasang event place mereka dengan cara mengumpulkan kartu artefak yang sesuai dengan peristiwa yang terkait.

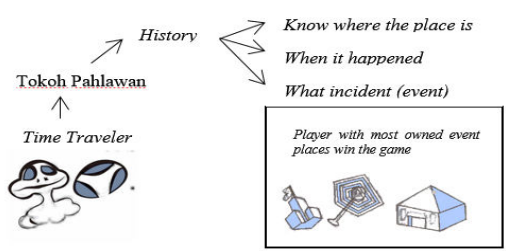


Konsep:

- Anak-anak diajak menjelajah waktu tertentu

- Mengenalkan tokoh/karakter yang terlibat dalam kejadian waktu tersebut

Gambar 2. Alternatif Roleplay

Pemain dapat menukarkan kartu yang mereka pegang dengan tumpukan deck setiap giliran. Masing-masing pemain dapat saling menyerang dan menghambat jalannya permainan menggunakan kemampuan khusus dari bidak yang berupa tokoh-tokoh pahlawan.

\section{Analisis Papan Permainan}

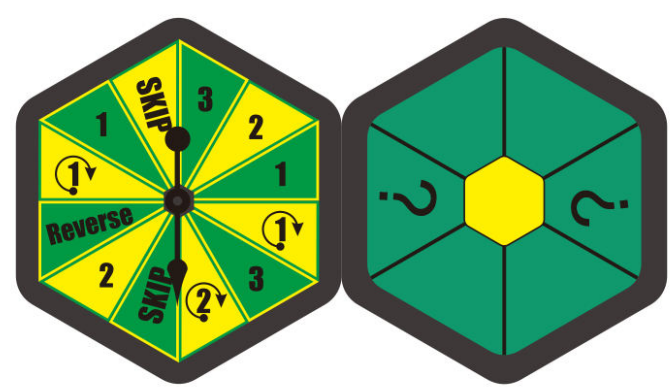

Gambar 3. Alternatif Papan Permainan

Papan permainan mengitari spinner board, akan tetapi papan permainan berupa modul yang terpisah dan memiliki bentuk yang sama dengan spinner board. Mekanik rute menjalankan bidak juga diberi 2 pilihan rute, yaitu rute pendek dan rute panjang, sehingga pemain dapat memilih sendiri jalan yang mereka inginkan. Alternatif ini juga memiliki trigger command dimana memiliki fungsi sebagai pembalik keadaan dalam permainan.

\section{Analisis Layout Kartu}

Berikut alternatif layout yang digunakan pada perancangan ini. Layout secara jelas menerangkan nama, keterangan waktu serta deskripsi dari peristiwa yang terjadi

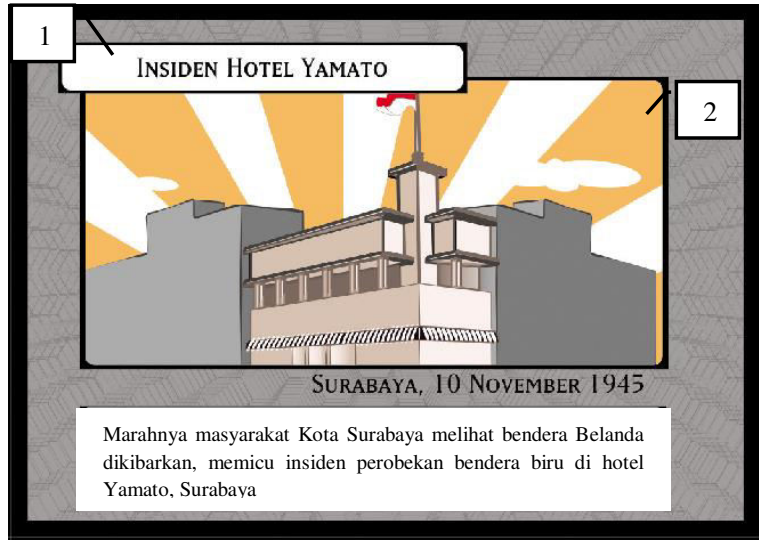

Perlawanan masyarakat Surabaya hanya menggunakan senjata bambu runcing. Salah seorang tokoh pemuda, Bung Tomo, ikut mengobarkan semangat pada masvarakat Surabava

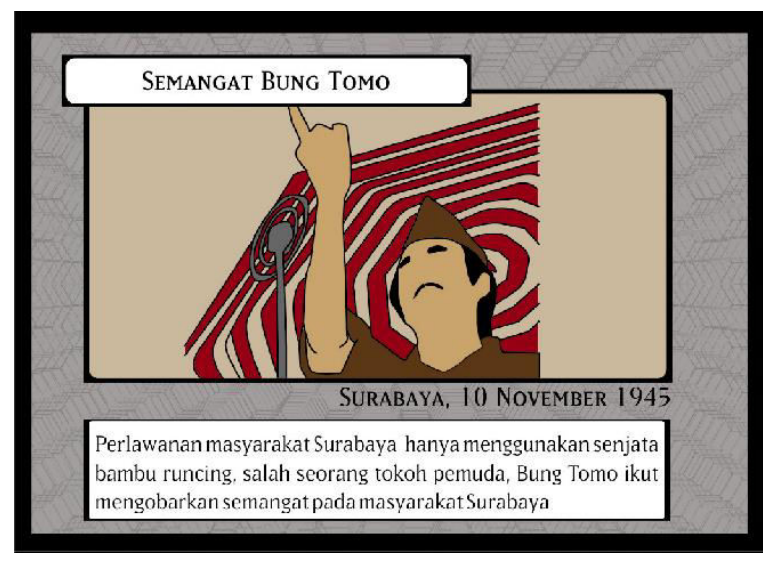

Gambar 4. Layout Alternatif Kartu

\section{Keterangan:}

1. Nama Event: Nama kejadian yang terjadi pada sejarah

2. Gambar Lokasi Event: Menunjukkan Suatu peristiwa sejarah melalui gambar.

3. Indikator Tahun: Tahun dan tanggal terjadi event sejarah

4. Deskripsi Gambar: Menerangkan peristiwa yang terjadi pada gambar

\section{E. Analisis Packaging}
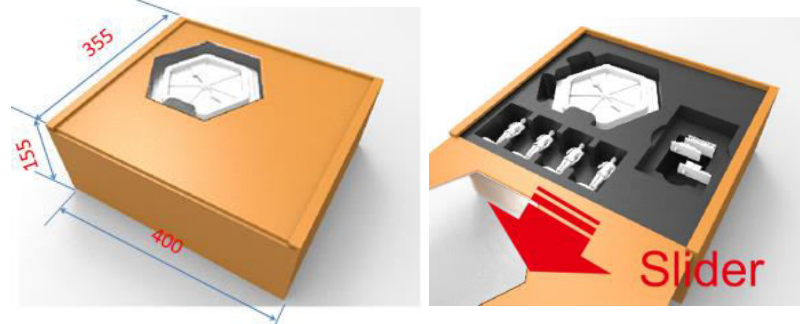

Gambar 5. Alternatif Box Packaging.

Bagian dalam kotak dibagi menjadi beberapa tempat, bidak, board dan spinner, event places, dan kartu artefak. Hal ini bertujuan agar kotak kemasan lebih terorganisir.

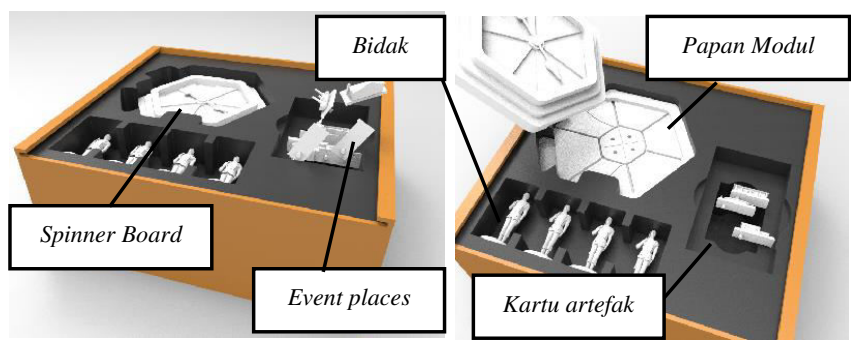

Gambar 6. Tampak Dalam Box Packaging

Packaging menggunakan material kayu mdf dengan proses produksi yang sama dengan spinner board yaitu laser cutting, box kayu memiliki visual seperti pada gambar.

\section{HASIL DAN PEMBAHASAN}

\section{A. Eksplorasi Ide}

Eksplorasi yang berawal dari sketsa brainstorming untuk memunculkan bentuk, serta konfigurasi yang sesuai untuk desain 


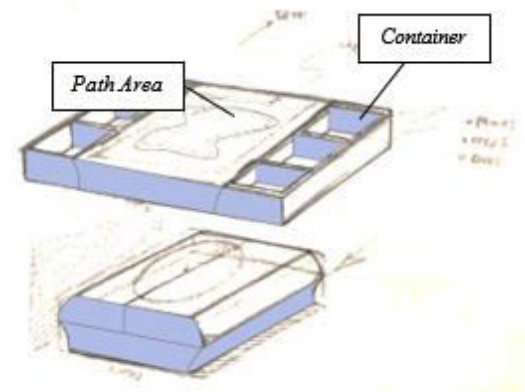

Gambar 8. Alternatif Desain

\section{B. Pemilihan Desain Alternatif}

Beberapa alternatif desain tersebut dikelompokkan kemudian dianalisis sesuai dengan kriteria riset dan desain hingga terpilih satu alternatif.

Tabel 1.

Pemilihan Alternatif Desain

\begin{tabular}{|c|c|c|c|c|c|c|c|c|c|}
\hline \multirow[b]{2}{*}{$\begin{array}{l}\mathrm{N} \\
\mathrm{o} .\end{array}$} & \multicolumn{2}{|c|}{ Parameter } & \multirow[b]{2}{*}{$\begin{array}{c}\text { Deskrip } \\
\text { si }\end{array}$} & \multicolumn{2}{|c|}{ Alt 1} & \multicolumn{2}{|c|}{ Alt 2} & \multicolumn{2}{|c|}{ Alt 3} \\
\hline & Item & W & & $\begin{array}{l}\mathrm{Sk} \\
\text { or }\end{array}$ & $\begin{array}{c}\text { Tot } \\
\text { al }\end{array}$ & $\begin{array}{l}\mathrm{Sk} \\
\text { or }\end{array}$ & $\begin{array}{c}\text { Tot } \\
\text { al }\end{array}$ & $\begin{array}{l}\mathrm{Sk} \\
\text { or }\end{array}$ & $\begin{array}{c}\text { Tot } \\
\text { al }\end{array}$ \\
\hline 1 & $\begin{array}{c}\text { Modular } \\
\text { ity }\end{array}$ & $\begin{array}{c}0, \\
5\end{array}$ & $\begin{array}{c}\text { Compa } \\
c t\end{array}$ & 2 & 1 & 4 & 2 & 5 & 2,5 \\
\hline 2 & $\begin{array}{l}\text { Aspek } \\
\text { Visual }\end{array}$ & $\begin{array}{l}0, \\
3\end{array}$ & $\begin{array}{l}\text { Tema } \\
\text { visual }\end{array}$ & 4 & 1,2 & 2 & 0,6 & 3 & 0,9 \\
\hline 3 & Clarity & $\begin{array}{l}0, \\
2\end{array}$ & $\begin{array}{c}\text { Layout } \\
\text { Permai } \\
\text { nan }\end{array}$ & 4 & 0,8 & 4 & 0,8 & 3 & 0,6 \\
\hline & Total & 1 & & & 3 & & 3,4 & & 4 \\
\hline
\end{tabular}

Keterangan:

$$
\begin{array}{ll}
1=\text { Sangat Kurang } & 3=\text { Cukup } \quad 5=\text { Sangat Baik } \\
2=\text { Kurang } & 4=\text { Baik }
\end{array}
$$

Gambar 7. Brainstorming Konsep Spinner dan Papan Permainan
Hasil ekplorasi ide akan dikelompokkan menjadi beberapa alternatif. Berikut beberapa desain alternatif yang dihasilkan.

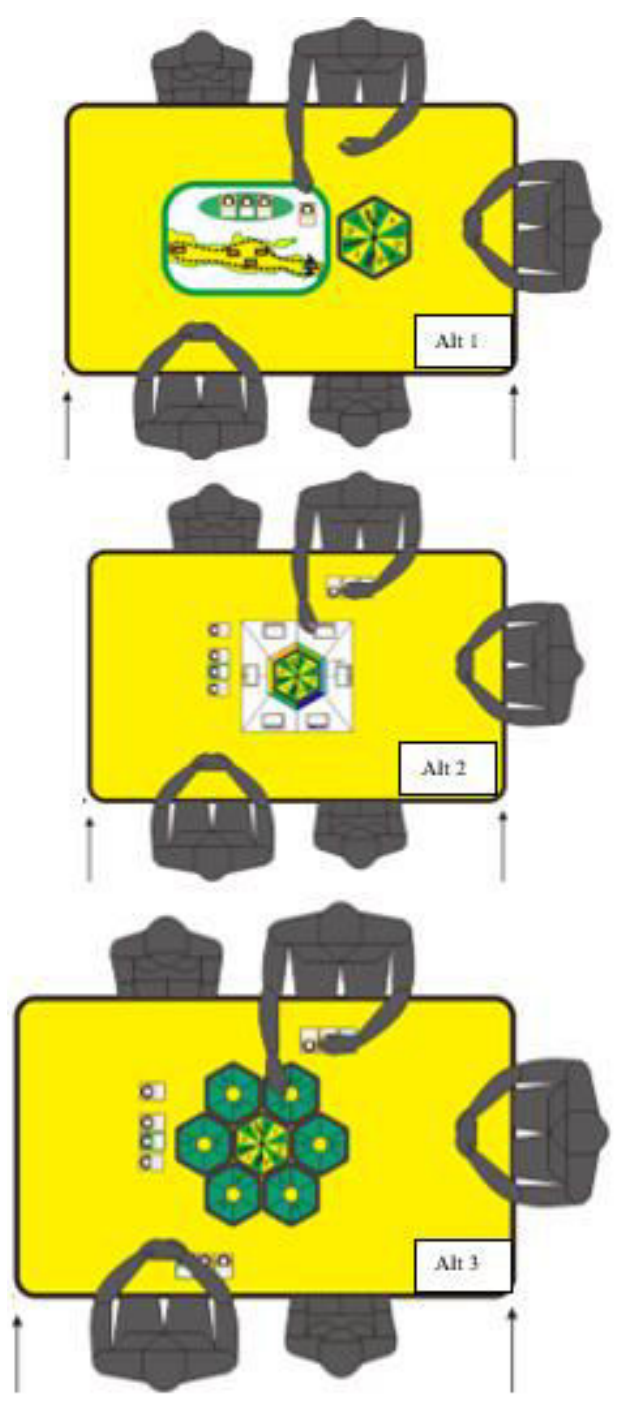

Angka penilaian 1-5 mengindikasikan nilai setiap alternative desain yang mengacu pada parameter yang tersedia. Berikut deskripsi masing-masing parameter:

1. Modularity $(0,5)$ : Aspek utama yang ditonjolkan pada produk ini. Ditujukan agar packaging produk mudah dibuat.

2. Aspek Visual $(0,3)$ : Aspek kedua yang penting karena dengan aspek visual dapat membuat poduk lebih diminati oleh user.

3. Clarity $(0,2)$ :_Adanya petunjuk atau area komponen pada boardgame tidak termasuk konsep utama dalam permainan, namun produk juga tetap harus memiliki unsur clarity ini seperti untuk menjelaskan jalur berjalan bidak, area peletakan event places, dan semacamnya.

Keterangan Skor:

Alternatif 1:

Alternatif pertama memiliki aspek modularity yang kurang (2), namun dari segi visual dinilai baik (4). Alternatif ini juga memiliki zona kartu dan spinner board yang jelas (4).

\section{Alternatif 2:}

Pada alternatif 2, skor yang didapat sudah baik untuk konsep modularity (4) bagian part boardgame dapat dilepaspasang menjadikan produk ini sesuai dengan konsep yang ditentukan. Tema visual pada alternatif ini kurang (2), layout permainan ini sudah jelas (4) area peletakan spinner, dengan papan permainan yang mengitarinya untuk berjalannya bidak

Alternatif 3:

Alternatif 3 memiliki nilai modularity yang sangat baik (5), bagian spinner dan papan permainan memiliki sambungan dan dapat dilepas pasang, segi visual yang ditawarkan cukup baik (3), aspek clarity memiliki nilai yang sama dengan alternatif 2 cukup baik (3)

C. Pengembangan Desain

1. Desain Event Places 


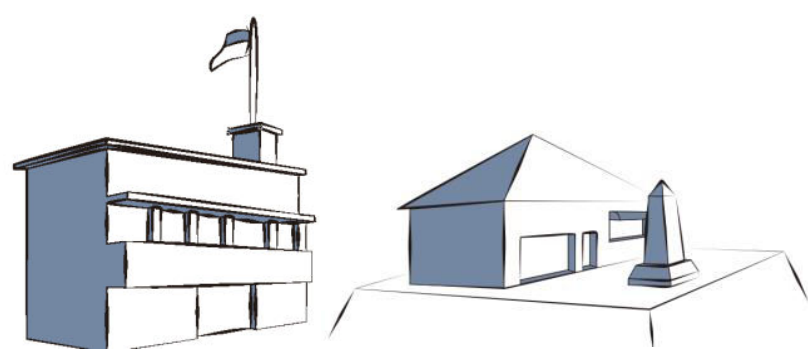

Gambar 9. Event Places

Event places bertema bangunan-bangunan yang menjadi ikon suatu peristiwa sejarah pada masa kemerdekaan. Bentuk bidak mengambil bagian depan dari bangunan yang ikonik tersebut lalu dibuat skala kecilnya.

\section{Desain Bidak (Pawn)}
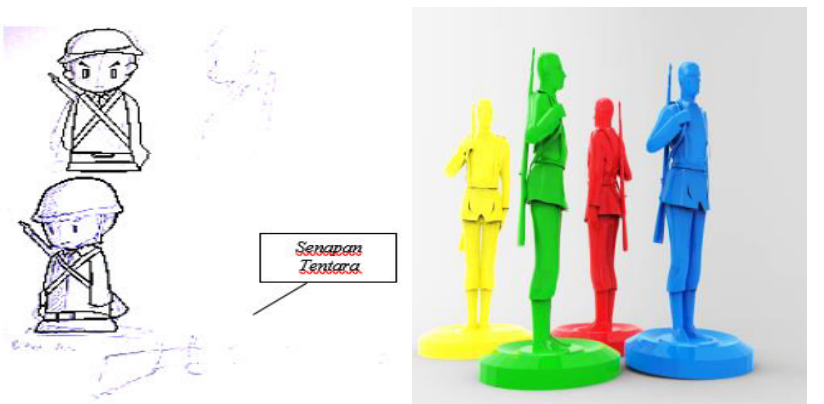

Gambar 10. Bidak (Pawn)

Tema bidak permainan mengambil karakterisasi dari prajurit yang siap ikut berperang pada jaman kemerdekaan, tema ini dipilih karena sesuai dengan tema inti dari konsep perancangan.

\section{Desain Akhir}

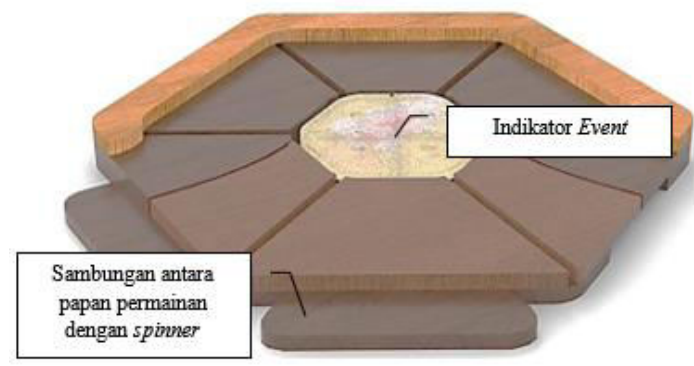

Gambar 11. Render Papan Permainan

Antara papan permainan dengan spinner board diberi mekanisme sambungan menyerupai sambungan dovetail.

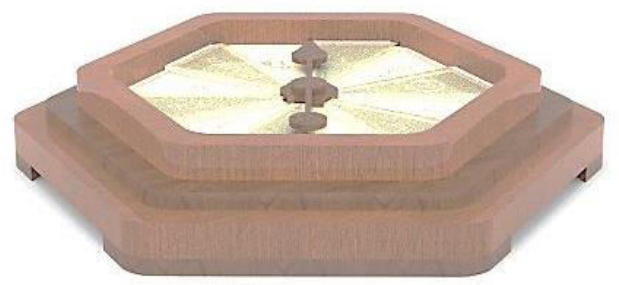

Gambar 12. Render Spinner Board

Mekanisme yang digunakan pada spinner adalah mekanisme pegas.

\section{E. Prototyping}

Proses prototyping yang digunakan pada pernacangan ini adalah proses $3 D$ printing untuk bidak dan event places, serta laser cutting untuk part papan permainan dan spinner board.

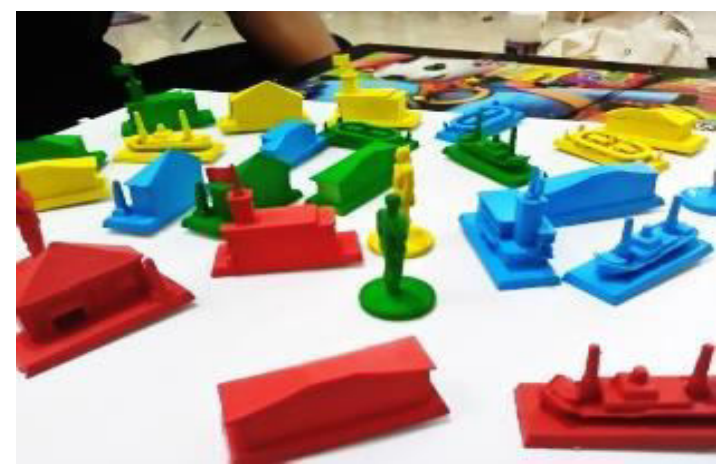

Gambar 13. Prototyping Bidak dan Event Place

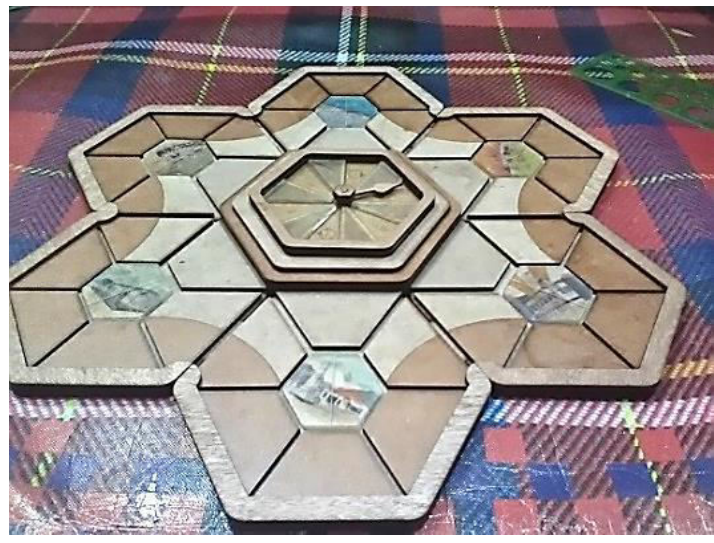

Gambar 14. Prototyping Papan Permainan dan Spinner board

\section{F. Usability Test (Playtest)}

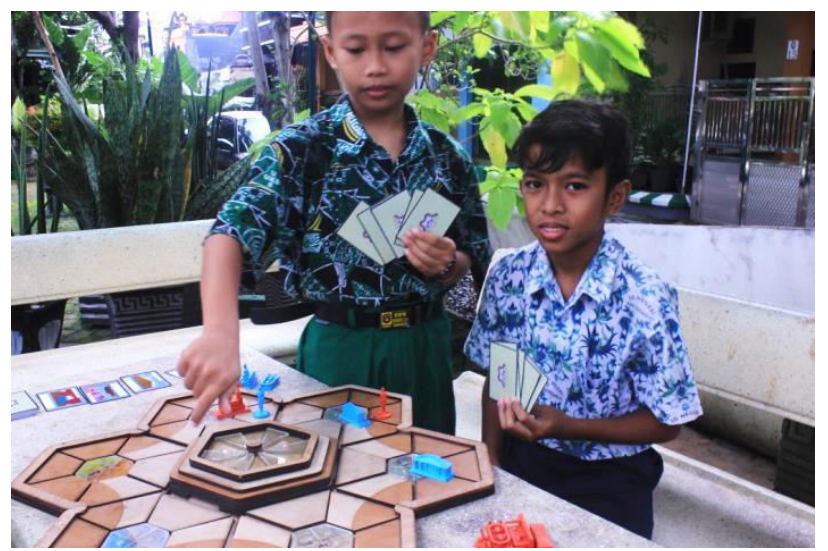

Gambar 15. Playtest dengan Target User

Uji coba permainan telah dilakukan pada target user, anak sekolah dasar kelas 5, dan mereka paham dengan materi yang didapat serta menikmati jalannya permainan.

\section{KESIMPULAN}

Beberapa hal yang dapat disimpulkan dari pembahasan diatas sebagai berikut:

- Konsep yang digunakan bertujuan untuk membantu para peserta didik untuk memahami pembelajaran sejarah.

- Konsep modularity digunakan karena dimensi permainan yang produksi sangat besar dan lebih ringkas apabila dapat dibagi menjadi bagian-bagian kecil.

- Roleplay yang diaplikasikan menimbulkan daya saing bagi setiap pemain sehingga timbul interaksi langsung diantara mereka. Pada permainan tersebut pemain juga dapat saling mensabotase satu sama lain dengan adanya mekanik tambahan berupa trigger events. 
- Packaging yang dihasilkan dibuat bersekat-sekat terbagi atas masing masing module boardgame serta komponenkomponen permainannya.

Penulis berharap produk ini untuk dikembangkan dengan penambahan sebagai berikut: lebih diperbanyak mekanisme pada permainan, tampilan grafis permainan yang lebih menarik, series permainan untuk materi pembelajaran yang lain atau sejenis namun dengan tema yang berbeda.

\section{DAFTAR PUSTAKA}

[1] I. Vitasari, "Kejenuhan (Burnout) Belajar Ditinjau Dari Tingkat Kesepian Dan Kontrol Diri Pada Siswa," Jurnal Pendidikan, p. 03 , 2016.

[2] E. Hardiyanto, "Kejenuhan Belajar Dan Cara Mengatasinya "Studi Terhadap Pelaksanan Pembelajaran Tarikh di SMP Muhamadiyah 3 Depok"," Jurnal Pendidikan, p. 2, 2009.

[3] J. Sulianto, M. F. A. Untari and F. Yulianti, "Media Boneka Tangan Dalam Metode Bercerita Untuk Menanamkan Karakter Positif Kepada Siswa Sekolah Dasar," Jurnal Pendidikan, pp. 94-104, 2014.

[4] b. arbai, "Menilik Pendidikan Generasi Z," 14 Desember 2012. [Online]. Available: http://www.kompasiana.com/arbai/menilikpendidikan-generasi-z_551afc2ea33311ea21b65bf5. [Accessed 2 Desember 2016].

[5] A. Sudrajat, "Generasi Z dan Implikasinya terhadap Pendidikan," 5 Oktober 2012. [Online]. Available: https://akhmadsudrajat.wordpress.com/2012/10/05/generasi-Z-danimplikasinya-terhadap-pendidikan/. [Accessed 18 Oktober 2016].

[6] L. Puspitowardhani, Interviewee, Boardgame for Education [Interview]. 15 Oktober 2016.

[7] M. Erna, Interviewee, Boardgame for Education. [Interview]. 15 Oktober 2016.

[8] Y. Rahmawati, "Pengenalan Budaya Melalui Bercerita," Jurnal Pendidikan Anak, 2012.

[9] R. Lueder and V. J. Berg Rice, Ergonomics for Children, London: Taylor \& Francis Group, 2008.

[10] B. Mayer and C. Harris, Libraries Got Game Aligned Learning through Modern Board Games, Chicago: American Library Association, 2010.

[11] kumpulanmateribiologisahabat.blogspot.co.id, "kumpulanmateri biologi sahabat," Desember 2013. [Online]. Available: http://kumpulanmateribiologisahabat.blogspot.co.id/2013/12/skenariomengarahkan-pembelajaran.html. [Accessed 1 Desember 2016].

[12] Melisa, "Menyelami Gaya Belajar Ala Generasi Z," Agustus 2016. [Online]. Available: http://majalah1000guru.net/2016/08/gaya-belajar- generasi-z/. [Accessed 2 Desember 2016].

[13] N. Howe and W. Strauss, Millenial Rising The Next Generation, United States: Vintage e-books, 2000.

[14] Badan Standarisasi Nasional, Standar Keamanan Mainan Anak, Jakarta: BSN, 2014.

[15] M. Csikszentmihalyi, FLOW The Psychology of Optimal Experience, New York: Harper Perennial, 1990.

[16] MichelleChanHL, "Deevana Plaza Krabi Aonang Photo: The Entrance," September 2012. [Online]. Available: http://www.tripadvisor.in/LocationPhotoDirectLink-g1507054d2293011-i50336675-Deevana_Plaza_Krabi_AonangAo_Nang_Krabi_Town_Krabi_Province.html\#48420902. [Accessed 9 Oktober 2015].

[17] F. Grieser, "PLA vs ABS: Filaments for 3D Printing Explained \& Compared," 14 Januari 2016. [Online]. Available: https://all3dp.com/pla-abs-3d-printer-filaments-compared/. [Accessed 15 Maret 2017].

[18] Mich, "What Material Should I Use For 3D Printing?," 10 Februari 2013. [Online]. Available: http://3dprintingforbeginners.com/filamentprimer/. [Accessed 15 Maret 2017].

[19] r. aufa, "Perkembangan Anak Masa Sekolah (6-12 tahun)," 9 Juni 2013. [Online]. Available: https://rahmaaufa.wordpress.com/2013/06/09/perkembangan-anakmasa-sekolah-6-12-tahun/. [Accessed 15 Maret 2017].

[20] G. A. Agoston, Color Theory and Its Application in Art and Design, New-York: Springer-Verlag Berlin Heidelberg, 1979.

[21] B. BRATHWAITE and I. SCHREIBER, Challenges for Game Designers "non-digital exercises for video game designers", United States of America: Cengage Learning, 2009.

[22] Menteri Pendidikan Dan Kebudayaan Republik Indonesia, Peraturan Menteri Pendidikan Dan Kebudayaan Republik Indonesia Nomor 24 Tahun 2016 Tentang Kompetensi Inti Dan Kompetensi Dasar Pelajaran Pada Kurikulum 2013 Pada Pendidikan Dasar Dan Pendidikan Menengah, Jakarta: Menteri Pendidikan Dan Kebudayaan Republik Indonesia, 2016.

[23] W. D. Hudhana, "Pengenalan Budaya Dan Pembentukan Karakter Melalui Folklor Pada Anak Usia Dini," Jurnal Pendidikan, 2014.

[24] T. Setyowati, "Menumbuhkan Kearifan Lokal Pada Anak Usia Dini," Jurnal Pendidikan, pp. 736-744, 2012. 